\title{
Panduan Praktis Pengiriman Naskah via Open Monograph Press 3.2 LIPI Press
}

DHEVI EIR MAHELINGGA

LIPI PRESS 2020 


\section{Penjelasan Singkat OMP}

Open Monograph Press (OMP) adalah platform perangkat lunak sumber terbuka untuk mengelola alur kerja editorial yang diperlukan untuk meninjau monografi, bunga rampai, dan edisi akademik melalui tinjauan internal dan eksternal, pengeditan, pembuatan katalog, produksi dan publikasi.

Sistem OMP mencakup proses penerbitan dan manajemen buku yang dapat dioperasikan oleh pengelola penerbitan secara fleksibel yang dapat diunduh secara gratis dan diinstal pada sebagian besar peladen web. OMP dirancang secara efisien untuk mengurangi waktu dan tenaga yang dibutuhkan untuk tugas-tugas substansial dan manajerial yang terkait dengan penerbitan buku sekaligus meningkatkan proses pencatatan dan efisiensi proses editorial. OMP dibangun untuk meningkatkan kualitas penerbitan ilmiah dan publik melalui sejumlah inovasi yang mencakup alur kerja yang jelas dan intuitif untuk setiap aspek pengiriman naskah, penelaahan, pengeditan, dan proses produksi. [1] 


\section{Silakan akses tautan: https://e-service.lipipress.lipi.go.id/press}


LEMBAGA ILMU

PENGETAHUAN

INDONESIA

INDONESAN INSTITUTE OF SCENAEES
e-Publishing

LIPI Press

Towards an Accreditited Scientific Publisher

\section{Klik Register}

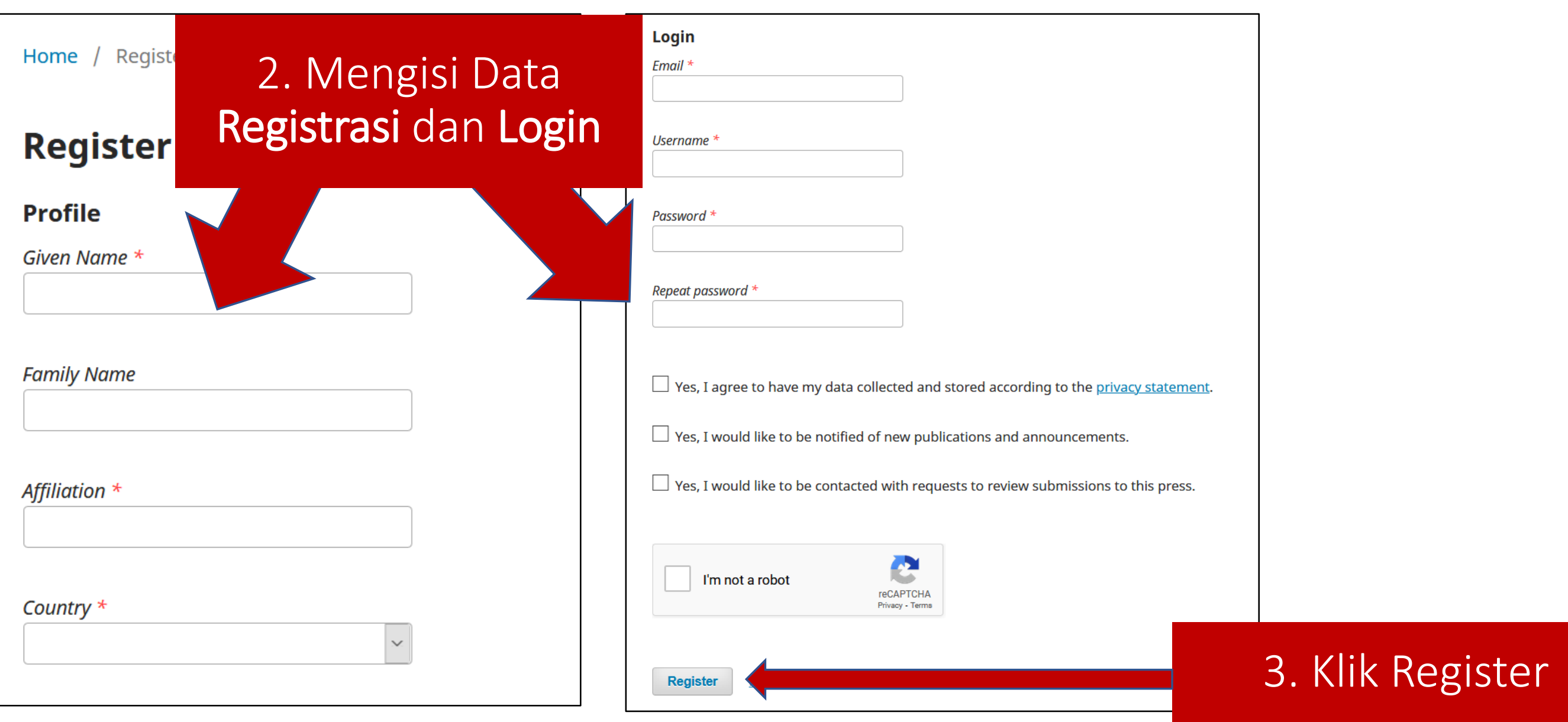


LEMBAGA ILMU

PENGETAHUAN

INDONESIA

INDONESIAN INSTITUTE OF SCIENCES
e-Publishing

LIPI Press

Towards an Accredited Scientific Publisher

Home / Registration awaiting verification

\section{Registration awaiting verification}

Selanjutnya akan ada email konfirmasi yang akan dikirimkan ke alamat email yang telah didaftarkan. Klik pada tautan email konfirmasi untuk bisa mengaktifkan akun Anda. 
Selanjutnya Anda bisa Login untuk bisa mengakses halaman Dashboard OMP

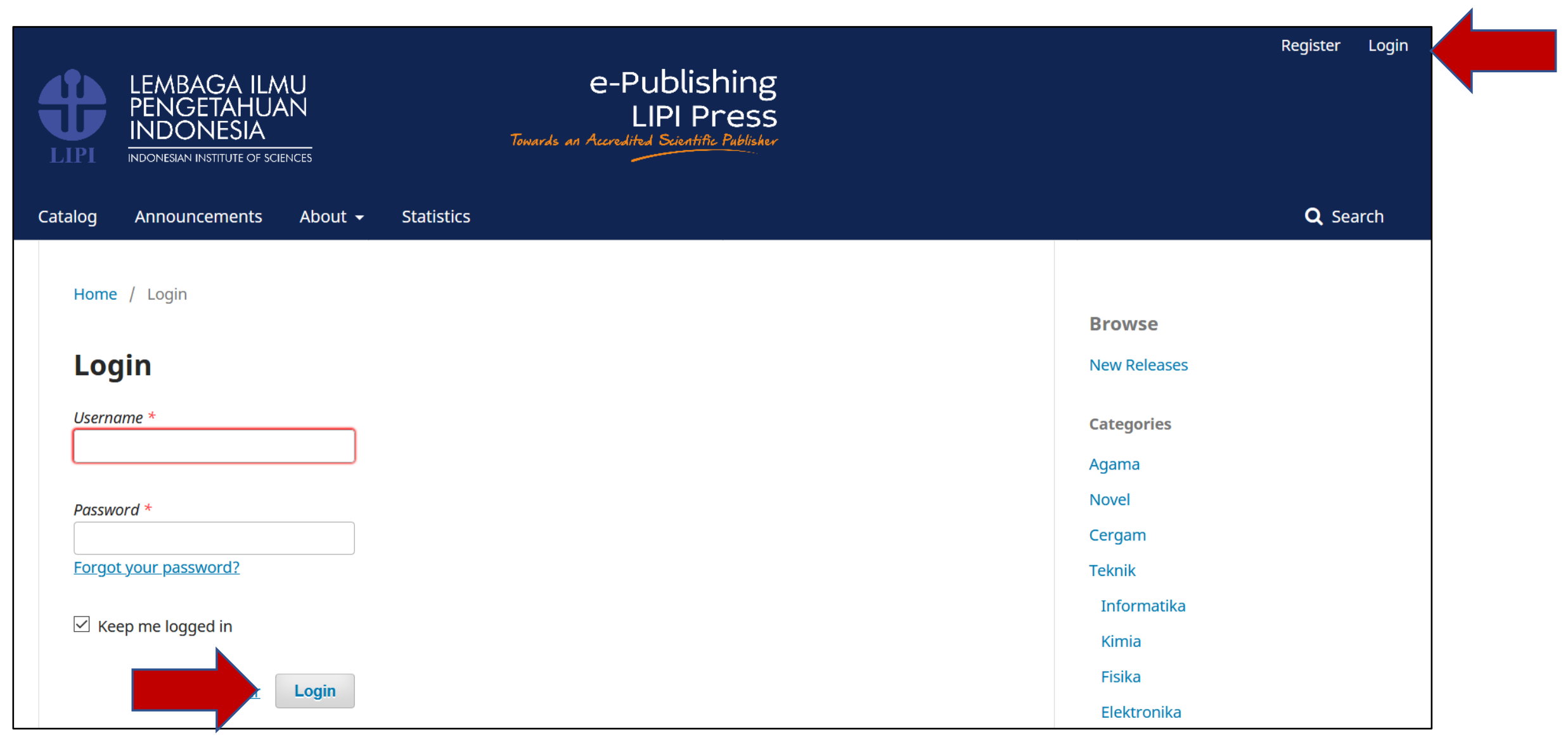


Sering Mampir Home-LIPI Press G Gmail @ Sasaran Kerja Pegawai...

LIPI PRESS Tasks 1

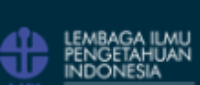

Submissions

\section{Klik Penulis Ialu} klik View Profile$$
\text { Profile }
$$

Identity
Contact
- English

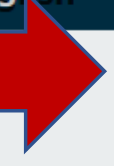

- View Site

3 penulis

\section{Roles}

$\square$ Reader

$\square$ Author

$\square$ Chapter Author

$\square$ External Reviewer

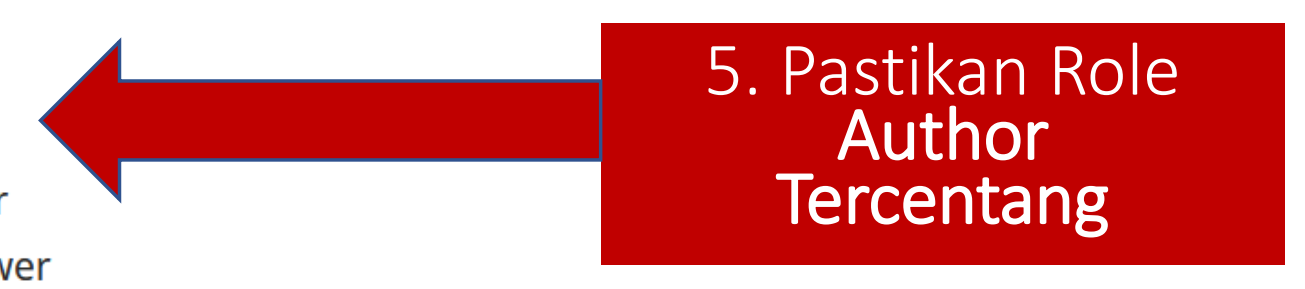

Reviewing interests

Save

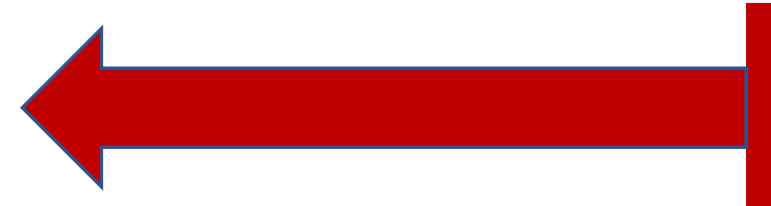

\section{Klik Save}

Your data is stored in accordance with our privacy statement. 


\section{Klik Submission}

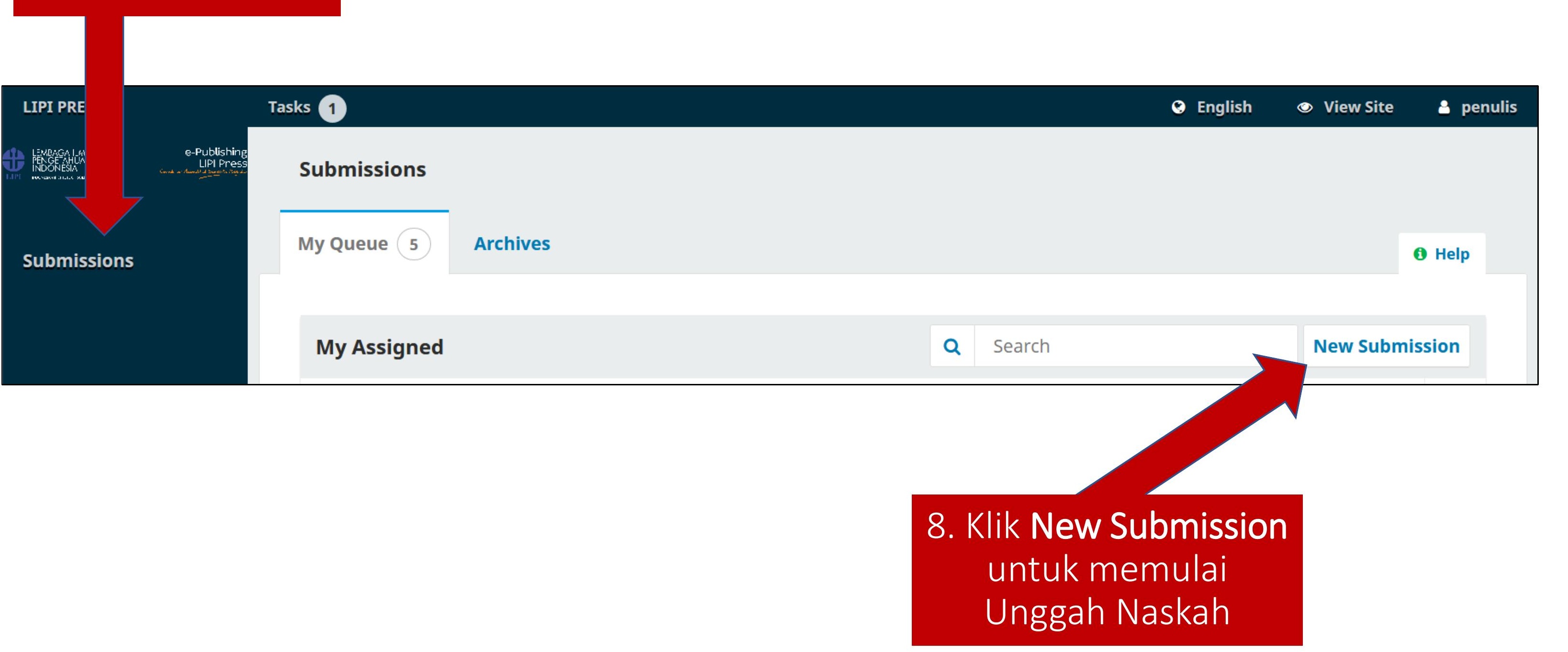



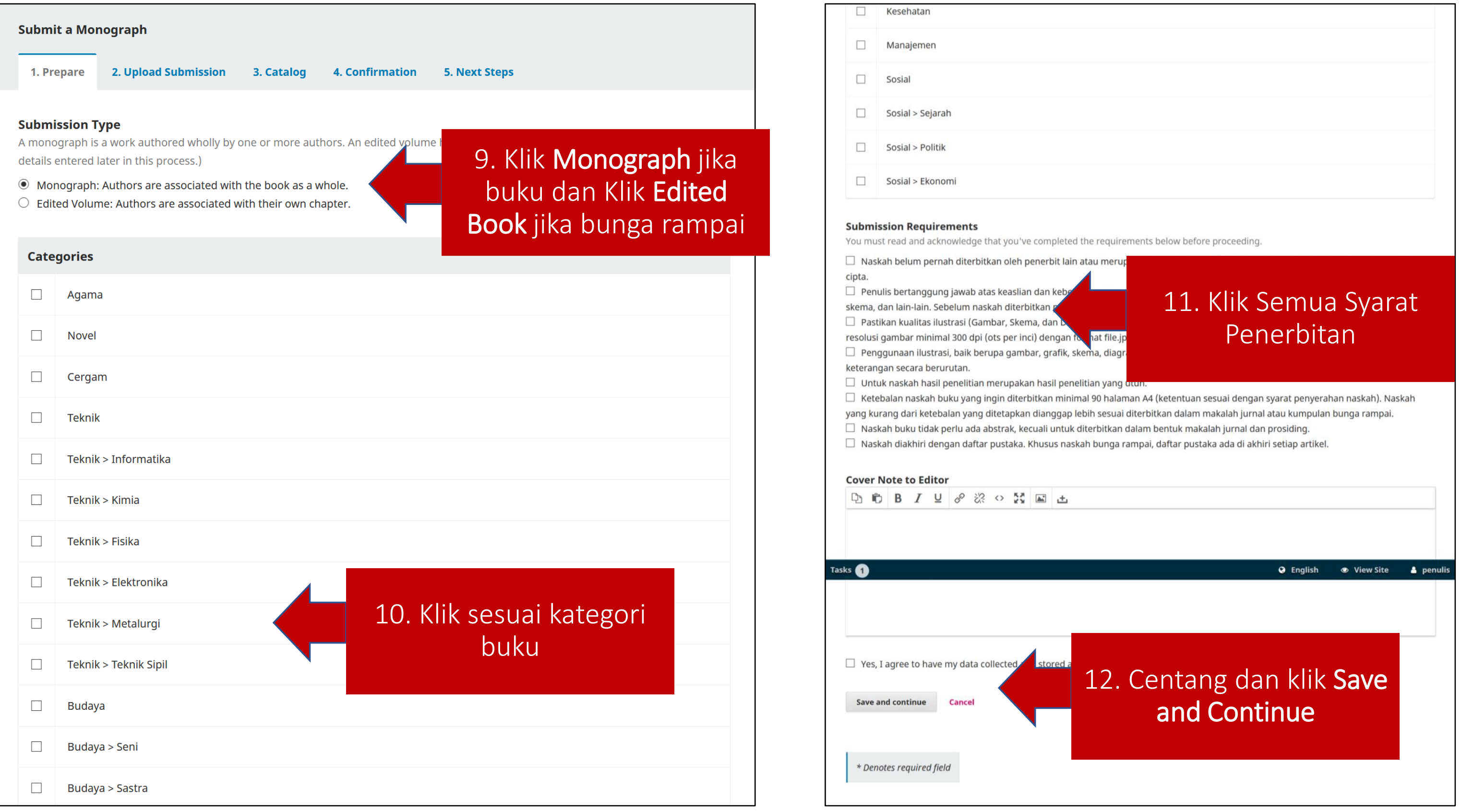


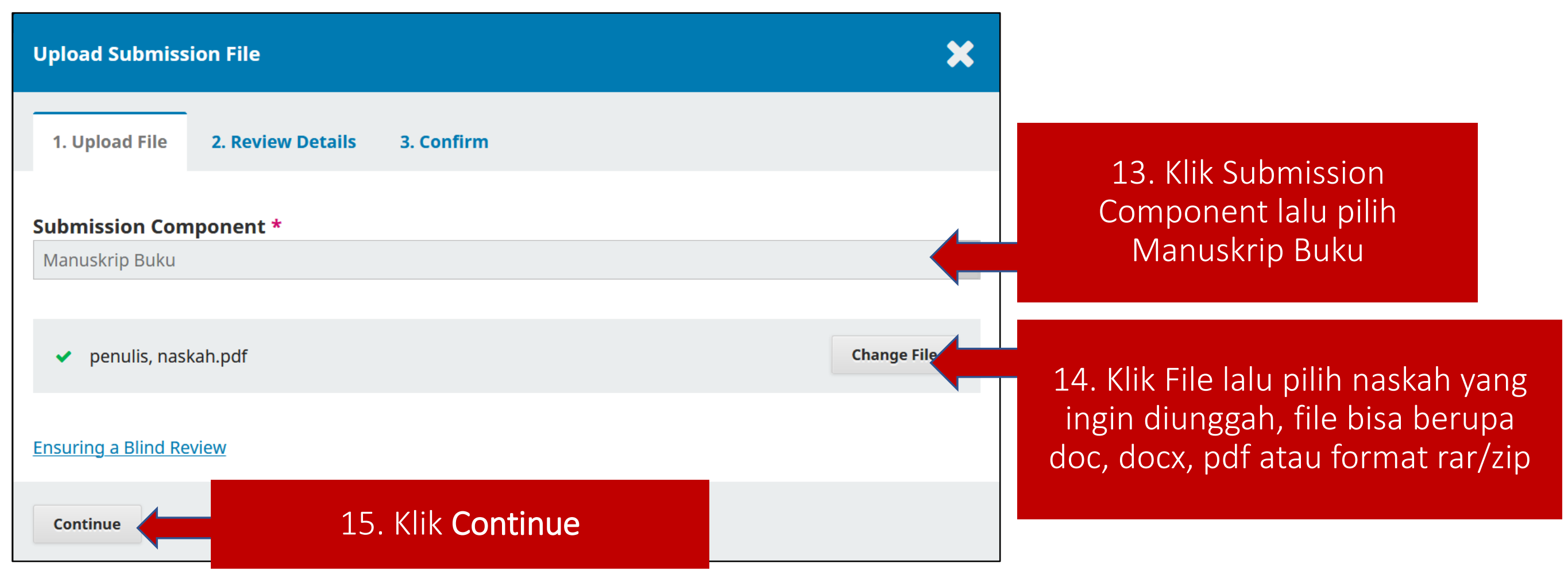

Upload Submission File

$\begin{array}{lll}\text { 1. Upload File } & \text { 2. Review Details } & \text { 3. Confirm }\end{array}$

penulis, naskah.pdf Edit 16 . Klik Edit jika ingin mengedit nama naskah
园 pdf $\boxminus 158 \mathrm{~KB}$

17. Klik Continue 


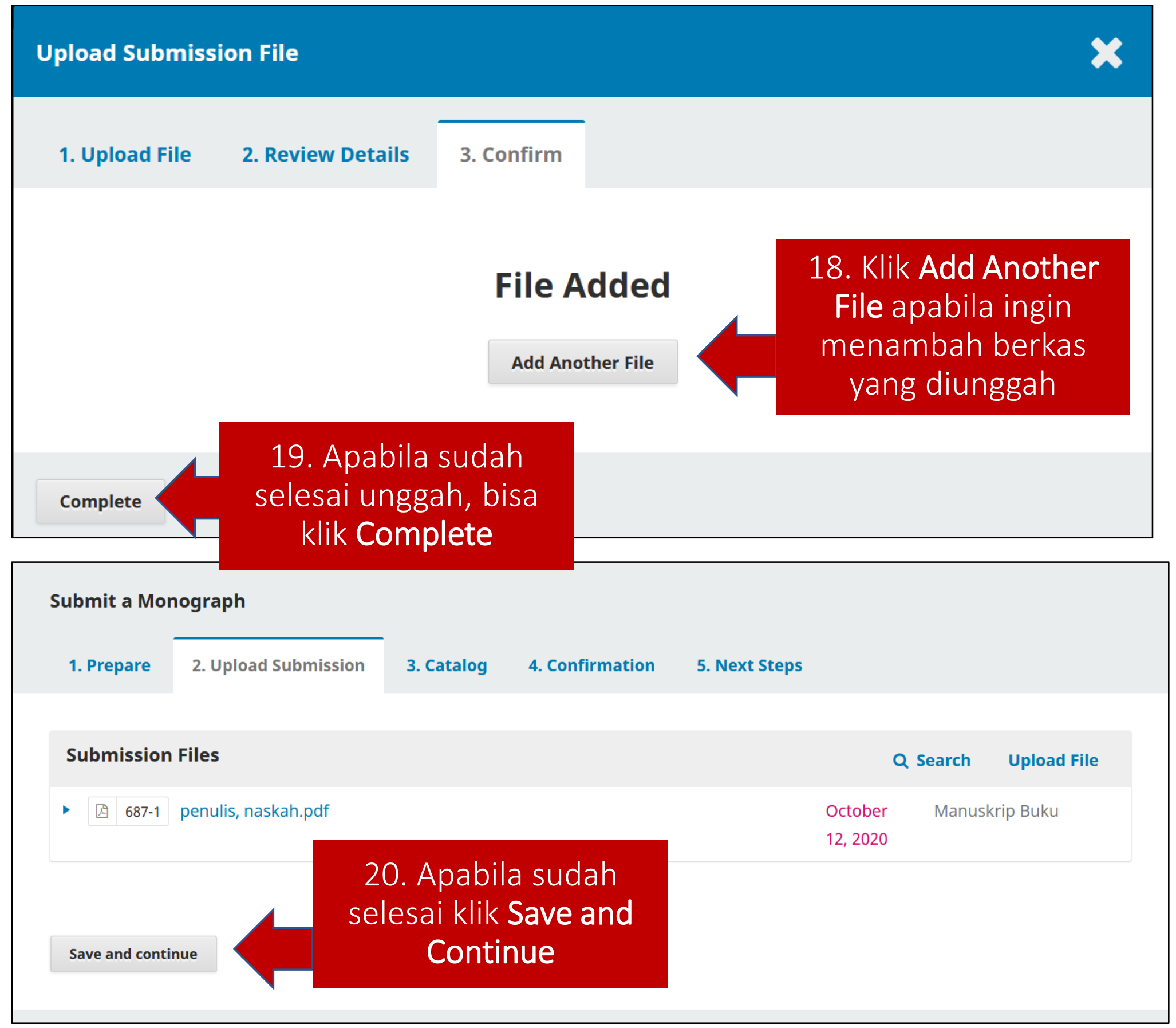


Submit a Monograph
1. Prepare
2. Upload Submission
3. Catalog
4. Confirmation
5. Next Steps

Prefix

Title *

21. Selanjutnya masuk ke catalog, isi Title dengan judul buku

Examples: $A$, The

Subtitle

Subtitle

Abstract *

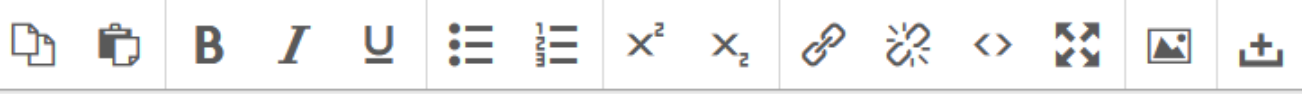

22. Isi Abstract dengan

abstrak atau sinopsis

buku 


\section{List of Contributors}

Name

E-mail

- penulis
23. Klik Add Contributor

apabila buku Anda memiliki lebih dari satu kontributor

penulis@lipipress.lipi.go.id

Author

$x$

Add Contributor

Name

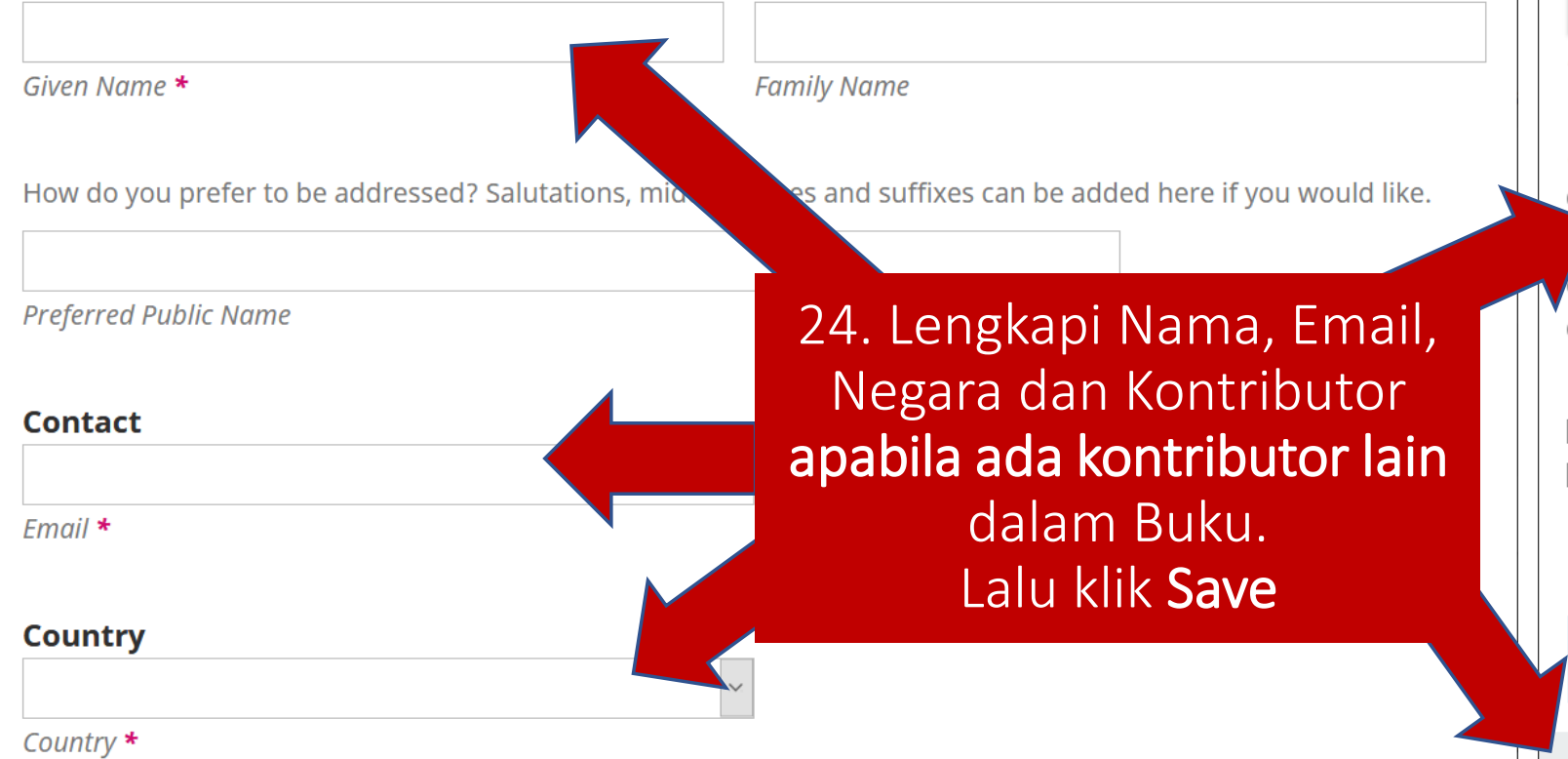

Bio Statement (e.g., department and rank)

Contributor's role *

Author

Volume editor

Chapter Author

Translator

Principal contact for editorial correspondence.

$\checkmark$ Include this contributor in browse lists?

- Denotes required field

Save Cancel 


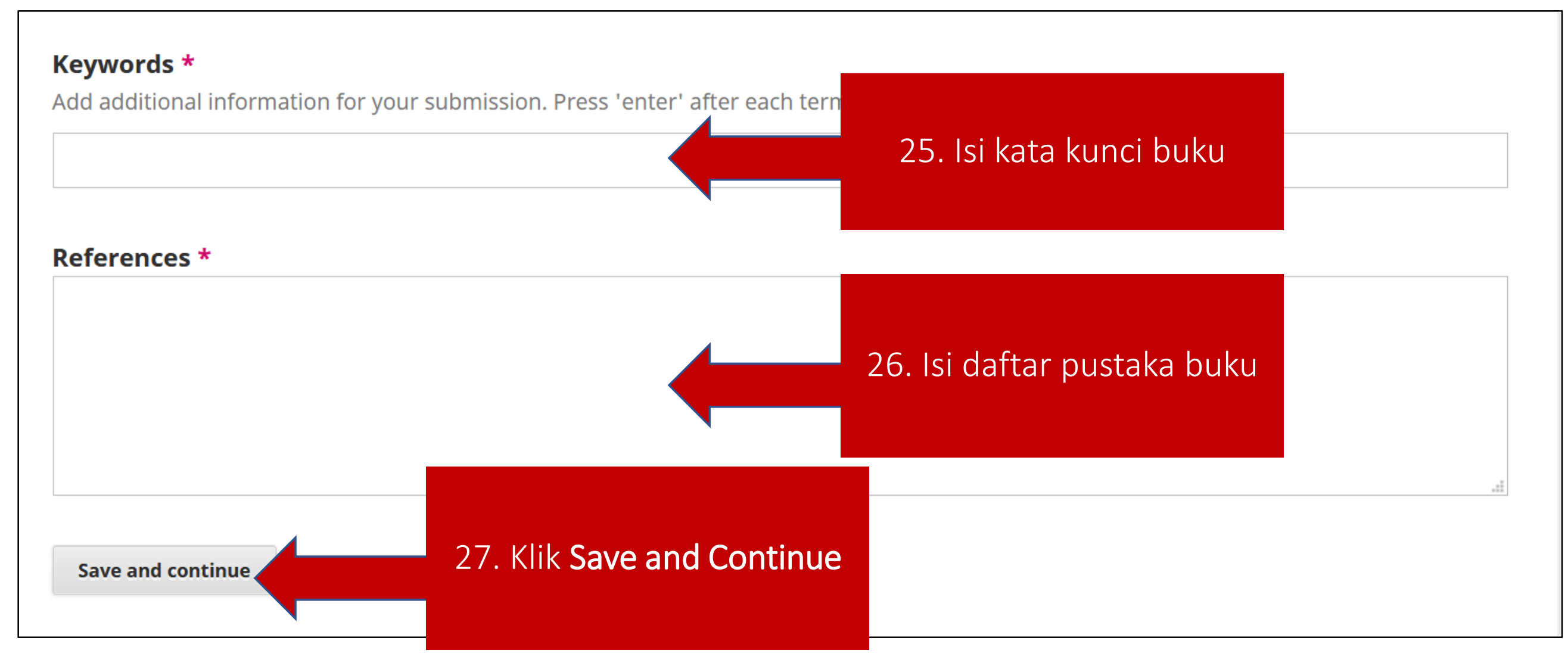


Submit a Monograph

1. Prepare 2. Upload Submission

3. Catalog

4. Confirmation

5. Next Steps

Your submission has been uploaded and ic roadven ho cont Voumaven hack to rovigw and adjust any of the information you have entered before continuing. When you are reac

Finish Submission

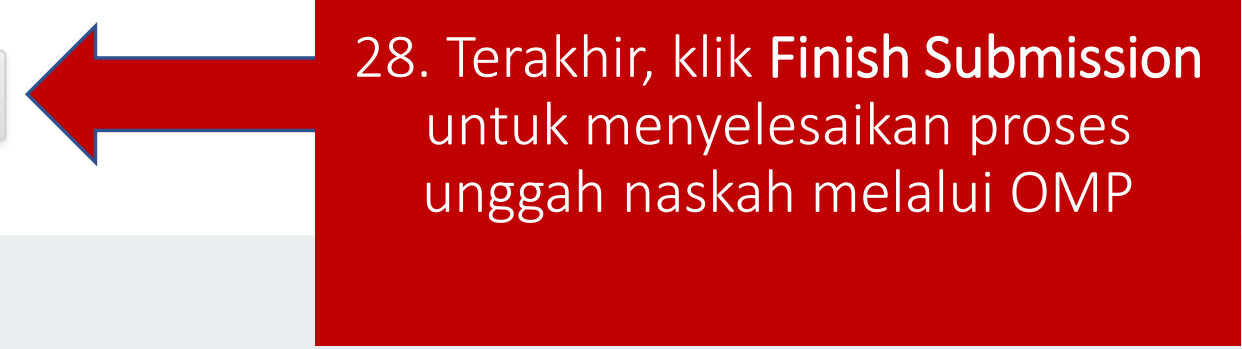

Platform \&

workflow by

OMP / PKP 


\section{Proses unggah naskah telah selesai. Selanjutnya naskah akan diverifikasi oleh Tim Editor LIPI Press untuk kemudian ditangani sesuai hasil verifikasi.}

\section{Referensi:}

[1] Mahelingga, D. E. I. R. (2020). Penerbitan buku ilmiah daring berbasis open monograph press (OMP). Berkala IImu Perpustakaan. 